\title{
3. Rediscovering Iconographic Storytelling
}

\author{
Vincent Amiel
}

Carlo Severi (2007) has rightly observed that, over a history much longer than that of cinema, both combinations of images and composed images have constituted another way of constructing meaning as complex, rich, and often just as narrative as combinations of letters or sound. This is what is often referred to today as "visual thought" or, as Francastel (1967) puts it, "figurative thought." It is a system of meaning specific to images, or their association, which owes nothing to the logic of writing. This form of thought has no need to be absorbed or circumvented by the same media which offer the largest choice of different images, with all their combinations and declinations.

It is true that the speed of projection, and thus of the persistence of images, remains an unavoidable condition of their effect; and we would have a hard time trying to compare film sequences with those of written or spoken text. However, long ago, cinema discovered ways of breaking the flow and finding a figurative diversity capable of producing links and networks other than those of written continuity. Thus, in the same way that there exists in certain forms of writing a graphic, or even an iconic dimension that affects or modifies meaning, cinema has many ways of dealing with images which offer a range of possibilities to create meaning (Schapiro 1970; Barthes 1970).

If we wish to avoid the totalitarianism of linear and chronological articulation, we can focus on two characteristics that contemporary screens have revived: the spatial configuration of images in relation to one another and the diversity of their forms.

Today, one of the first consequences of the widespread use of personal screens has been the new experience of the spatial arrangement of screens and their frames. On computer or mobile phone screens, images and frames are moved, interlocked, and zoomed in or out according to the viewer's will. Thus, the images and frames interact with each other. An algorithmic logic, which takes on some of the autonomous, self-consistent characteristics of fiction, allows images to appear, and to modify, transform or follow one another, thus turning upside-down our habit of distinguishing the frame from the background. Here, I am referring to the so-called "cookies" 
that pop up for advertising or informational purposes. Images appear and confront one another - at least according to the order and hierarchy of perception - but they also dissolve into one another, quickly becoming oblivious of their own frame. On touch screens, the void around figures and signs is not considered a part of the image, but as a useful area able to be filled up. The very notion of "background" disappears, as in the use of the term "wallpaper" for screen background (in French, fond d'écran). This is not part of the image related to the foreground, but is an autonomous, indifferent space, a neutral surface on which multiple icons appear. Thus, the image loses all characteristics of a framed whole that it has acquired during the classical tradition. ${ }^{1}$ In this respect, it has returned to the way Schapiro described images in the Middle Ages: "the frame belongs to the viewer's space more than the illusory, three-dimensional one that nests within its limits" $(1970,12)$. This inscription of several frames on one screen, of several images that can be seen at the same time, may be considered archaic. Lately, however, we have grown accustomed to it, and so quickly that one wonders whether cinema had ever renounced it. Evidently, it had not and, in a way, cinema has remained a privileged vehicle for it. But the inscription process displayed itself discreetly, marginally, as though sucked into the accelerating flux of images and their singular meanings. We are interested here in such combinations of images: images inscribed in the unfolding process of a film but which, for the duration of a shot or a sequence, suggest discontinuity or a different logic of articulation, thus establishing links that hardly relate to classical narrative logic.

\section{Four Examples}

Here, we shall consider images that a film marks as alien, resisting the narrative flow to which they belong. Furthermore, we shall focus on their interplay. For instance, they create a competition between the points of view associated with them at the time of their appearance, between the strength of their significance as well as their degree of representation. These characteristics make them different from one another, causing them to clash and separate from the flow in which they are supposedly integrated. There are four such types:

- The first type includes multiple images on the same screen. While these were once arranged in quarters or chequered in the era of silent cinema, they are currently presented in what is commonly referred to as split 
screen. Thus, three or four images can be placed next to one another on the same screen, but at different speeds and for different durations. "Split screen" makes simultaneity both effective and possible ("meanwhile ..."). Different points of view are able to coexist ("leaning, one could have seen ..."). In addition, however, there can be unlikely conjunctions of different realities, whose correspondence may, at first, seem odd. These first types are the most frequent, ${ }^{2}$ but they are also the least specific, since they could easily be replaced by a traditional editing structure which has consecutive scenes or shots signifying simultaneity - one of the common functions of insert shots. The third example is more interesting, because it does not follow a cause-and-effect logic, and is not part of the narrative flow. It involves such plastic elements as colors, rhythms, and types of image. An early example would be the famous pillow battle in the dormitory, in Abel Gance's NAPOLÉON (1927).

- Such images do not merely share the screen, but can be superimposed on it. This overlaying technique was often used by Gance and other experimental filmmakers of the 1920s. Two, three, or more overlays of images are visible to the viewer. While it is sometimes difficult or even impossible to distinguish one layer of image from another, the principle remains explicit. The final shot of Anthony Perkins in Alfred Hitchcock's Psycho (1960) uses this process in a peculiar way: it superimposes the face of the son on the mother's and relies on the viewer to consciously combine the two images. It is the same with green- or blue-screen chroma-key special effects, which substitute a different background for a figure photographed against a solid color. ${ }^{3}$ Instead of remaining undetectable, as they normally do, these can make one aware of the hybrid quality of the shots in question. Caroline Renouard has brilliantly demonstrated how this is done in L'ANGLAISE ET LE DUC (2010). Eric Rohmer makes two eras interact with one another by superimposing two types of images in the same shot (Renouard 2012, 410-419).

- The third form of image association involves explicit inlays, meaning that these are not used to achieve a trompe-l'oeil effect. I am referring to widely used effects that video has multiplied, first on television and then on cinema and computer screens. These inlays consist of "windows" within a mother-image, a window in which a different action takes place and another reality is shown. Examples include the inlays opening during television news programs, which the French television artist Jean-Christophe Averty has turned into a playful game. Referred to as "icons" on computers and mobile phones, they allow one to proceed from one layer of content to another. Such inlays allow for intellectual 
trajectories, classification, comparison and removal: in other words, more than merely following a story. The process was seldom used in films until it was developed by video; now it offers the opportunity to create complex links between images by articulating, for instance, the relative status of encompassing and inlayed images, hence of primary and secondary events.

- Finally, there are images that establish yet another level of difference from their neighbors: object-images that form part of the diegesis, book covers, posters, television or film screens, and paintings. Filmmakers, such as Godard, Hitchcock, and Rohmer, have consciously multiplied the articulation of these images within the shots of their films. Between the explicit meaning of these images and their potential connection with others lie the most obvious difference and articulation of visual thought from conventional narration that we are trying to distinguish. A poster on a wall may be connected with a social or dramatic context; scenes watched on television may feed into the story in which a character is involved. These are simple narrative links that contribute to the linear and contextual reading of a film. However, if a painting or any other type of object-image is related to the story in a more complex way and is free from a strictly directional vision, this is typically an example of what such images can produce. ${ }^{4}$ Thus, the object-image, first identified as being part of a set, is legitimized as well as erased by the diegetic realism; it then becomes an inlaid entity which is able to establish complex correspondences with the rest of the film, through its meaning, plot relevance, or any of its formal elements.

Therefore, by way of collage, overlay, inlay, or objectification, offset images complicate the flow of films, generating networks, ridges, or narrative systems that deliberately confuse the course of the film. They are indeed offset because of the way they appear, their specific forms, and "medial" situation; the element of mediation, one might say, which they allow to appear and which constitutes them. By way of a simple effect due to usage - which is actually intrinsic to the very notion of image - it is when they multiply within a single frame that they actually reveal their nature as images; when their succession does not, in any way, affect the transparency of their representation.

This auto-eidetic dimension of the image should not be minimized: it is by departing from the apparent evidence of its mimetic storytelling that cinema is able to escape prevailing narrative habits. The power of realism is such that, since the beginnings of cinema, its effectiveness has a stunning effect. A deliberate deviation, an explicit shift is necessary for another logic 
of meaning to appear - or to insinuate itself in a more discreet way. Within the apparent movement of elements of the diegesis, which immediately establishes the possibility and necessity of a story, it is essential to create a visible rupture, not only in the form, but also in the system of images.

\section{An Iconographic System?}

It is common to place the iconographic and narrative systems in opposition to one another, as though specific qualities inherent to the very principle of the image were unable to merge with the storytelling process. The opposition, however is false because, for the most part, it focuses on one image, in other words, a single moment or situation within the flow that is inherent to narration. The two opposing systems generate another classic polarity: description and narration. No quality inherent to the image is at stake here, unless one considers the image as unavoidably static - which cinema itself contradicts. Thus, if one considers a plurality of images in space and time, it is legitimate to wonder how they can make sense when taken out of the story, or how they can make sense as a narrative. If, indeed, there is such a thing as an iconographic system, it is not opposed to a narrative or any other discursive or demonstrative system. An iconographic system would be contrasted with a vocal, linear, one-level system, as is mostly the case with the written system. In other words, image is not to be opposed to narrative, but to time-regulated narrative. In oral and written traditions, ephemerality and fluidity regulate the economy of story and its reception: thus, it is necessary to find stable points within it. The notion of "narrative identity" (identité narrative) proposed by Paul Ricoeur (1985) refers to oral (or written) narrative resisting its own mechanism. It establishes the narrative's need to maintain some kind of permanence within the never-ending transformation generated by temporality. However, this reflection about identity would not occur if there was no transformation, no constant fading of shapes and figures. What is precisely impossible as far as the image and cinema are concerned is the capacity to maintain the successive stages of a story in some kind of timeless simultaneity. Split screen and superimposition allow for the copresence of two realities, not separated by any chronological gap. According to this schema, simultaneous images convey some kind of timelessness, a lack of succession, the disappearance of temporal order. And if there is memory, causal explanation, or time-shift (all cinematic processes that are common in classic cinema), these constitute specific cases established by the screenplay and are expressed through conventional 
effects (dissolve, iris, etc.), which exploit the intrinsic properties of the image. The frequency of their occurrence (like, for instance, the obsolete topos of dissolving on somebody's face to imply memories) cannot hide this particular character: coexisting images merely accidentally imply time-shift.

What the image is able to dispose of is what Pierre Bergougnoux (2016) refers to as "rational storytelling," which he defines as being bound by some conventional rules: the fixed identity of characters; the spatio-temporal orientation of the universe in which they move; and strict observance of the causality principle.

Bergougnoux contrasts "rational storytelling" with children's storytelling, or "the text of dreams"; but also with mythological narratives or the first great primitive stories, such as Gilgamesh, which are totally free of such rules. This is obviously very close to Carlo Severi's observations on visual thought in nonwritten traditions.

Such visual thought literally disorganizes the narrative, by refusing the rationality invoked by Bergougnoux, which relies completely on temporal linearity. Strict causal articulation and maintenance of the same conditions disappear when temporal flow is replaced by a chequerboard of random movement. This is what happens when different evolutions, a-chronological situations and independent rhythms coexist in one image as revealed by the history of art in tympana and altarpieces. The image is not necessarily organized around a story that imposes an unequivocal unfolding. According to Ricoeur, it maintains "discordance" while the narrative project builds up "concordance." It is not that the image has banished time or ignored the story, but rather that it has multiplied them. Within the image, one can find dramatic scenes that are both dependant on and independent of one another. Thus, image is not Story (récit), even though it is constituted by stories that establish meaningful links. It is not Story because the only unity it confers on the discordance is a formal one; it does not integrate:

the quality of narrative intelligence (which consists in) incorporating discordance into concordance, with the effect of surprise playing a part in generating meaning; the consequence is that, afterwards, the fable seems probable, or even necessary. (Ricoeur 1992, 472)

Nevertheless, it enables these stories to co-exist, maintains each story's autonomy and keeps them from scattering. A kind of unity is achieved because they coexist in one frame, on one support, in one space, and are able to be taken in simultaneously at a glance by the viewer. This is why copresence on the screen is so important; the spatial link it establishes 
balances the movement generated by the projection of images: a concordance through becoming (parle devenir).

What Ricoeur refers to as "narrative identity" maintains a single identity through the story's continuity in spite of occasional discordance. The process is at work in film because of its very movement, but it is negated, or at the very least unbalanced due to coexistence on the screen. When a window is opened in a John Ford film, or when a superimposition appears in Truffaut, it is another image, perhaps narrating something subordinated to time; but, most of all, it is another meaning relationship that appears to the viewer. In the overlay of two images, in the embedding of one frame within a shot, it is the determination of each image that disappears, though not completely, creating a new potential. The correspondences of one image to another can, of course, be secured by the story - integrated by concordance - as reminder, premonition; but, most of all, they can introduce something radically different.

\section{Random Connections}

Spatializing the links between images means relieving them of their temporal conditioning, freeing them from strict graphic-narrative conformity. This means not only allowing them to escape a strict determination of their layout and reception, but also simultaneously establish between them original sensory effects. These can belong to two orders, namely discourse and inner flow (or, to use William James's term, "stream of consciousness"). The point is not to follow the objective and apparent evolution of persons and objects, but to suggest by the relation between two images, a different movement, which could be that of discursive thought, external to phenomena, or of intuitive inner thought.

When Hitchcock puts a print of Susanna and the Elders on a wall (in Psycho) or when Arnaud Desplechin makes his main character describe The Arnolfini Portrait (in Les FAnTôMES D'IsMAEL, 2017), we can feel these paintings' presence, making a formal link with the films, comparing the plots or structures of the two image systems, and so illuminating the films through these connections. On the other hand, when in Рsycho, the skull of Norman Bates's mother is superimposed on her son's face, or when an infinite desert landscape appears in a window in THE SEARCHERS (1956), it is by intuition, through an intimate understanding of the object, that a new, supplementary meaning appears. There are so many discordant elements within the primary story, which constitutes a succession of events, that 
neither the Fordian landscape nor the Hitchcockian disturbed personality belong to any chronological order. However, we recognize that they are neither foreign to the story nor secondary to the work as a whole: they are the very substance and flesh thereof, beyond any need for explanation. Born of the relations between images, they are as free from time as from conventional realism. ${ }^{5}$

But they do belong to the story; in fact, they constitute it. By introducing a timeless element, they open up a field of possibilities. The mechanics of cause and effect no longer apply, since spatial cohabitation generates an all-round potentiality. ${ }^{6}$ The spatialization of images is therefore not against the story, nor around it. It is the story itself that gains a new dimension: characters can change their situation and, in time, their status. For instance, a daughter can experience what her mother has experienced, the dead can go on living, and timelines can cross one another. The open frames (cadres ouverts) in Tarkovsky's or Parajanov's images point to an eternity within a finite world; Wenders's video monitors in ToKYo-GA (1985) suggest the possibility of a universal nomadism. Times collide, causalities disappear, and identities dissolve.

For all that, the simultaneity of images, which is achieved by avoiding consecutive presentation, and offering the possibility of storytelling unconstrained by succession, allows something that perhaps was hidden in the editing process to appear in broad daylight. When images establish a dialogue on the same screen, they show how relative and conventional this succession is, as well as how legitimate it is to consider the relations between images in a nonlinear logic. It implies that it would be well-founded to envisage the links between images in a nonlinear logic. Then a new conception of storytelling appears.

\section{Notes}

1. "The edge (the physical edge of the panel and the represented edge in painted architecture) is the active limit of the representation; thus, it acquires the function that it will have in classical painting, assuring and confirming the inner autonomy of representation from the outside world (even if it has to be doubled by a material frame)" (Arasse 2010, 66-67; translation Ian Christie). See also Stoichita: "The frame separates the image from what is not image" (1999, 53; translation Ian Christie).

2. As in the famous The Thomas Crown Affair (Norman Jewison, 1968) or in The GrifTERs (Stephen Frears, 1990), or in almost any film by Brian De Palma. 
3. Digital chroma-key has replaced the background substitution which used to be provided by matte processes.

4. Michael Haneke's films, such as BENNY's Video (1992) and FunNY Games (1997), use television screens in a way typical of these articulations. One can also refer to the essays of Vancheri $(2013,2015)$.

5. Some descriptions in Flaubert are of such an order: extraneous to the narrative, but still constituting it.

6. This could be compared with Gilles Deleuze's “images-cristal," as having similar characteristics.

\section{References and Further Reading}

Arasse, Daniel. 2010. L'Annonciation italienne. Paris: Hazan.

Barthes, Roland. 1970. L'Empire des sens. Genève: Skira.

Bergougnoux, Pierre. 2016. Raconter. Bordeaux: William Blake and Co.

Francastel, Pierre. 1967. La Figure et le lieu. Paris: Gallimard.

Renouard, Caroline. 2012. "Les effets esthétiques et narratifs de la technique de l'incrustation." PhD diss., University of Paris-Est.

Ricoeur, Paul. 1985. Temps et récit III. Paris: Seuil.

-.1992. Lectures 2. Paris: Seuil.

Severi, Carlo. 2007. Le Principe de la chimère. Paris: Musée du Quai Branly.

Schapiro, Meyer. 1970. Style, artiste et société. Paris: Gallimard.

Stoichita, Victor. 1999. L'Instauration du tableau. Genève: Droz.

Vancheri, Luc. 2013. Psycho. La leçon d'iconologie d'Alfred Hitchcock. Paris: Vrin.

-. 2015. La Grande Illusion. Le musée imaginaire de Jean Renoir. Lille: Presses Universitaires du Septentrion. 
